\title{
Comparative Techno-Economic and Exergetic Analysis of Circulating and Dual Bed Biomass Gasification Systems
}

OPEN ACCESS

Edited by:

Daniel Florez-Orrego,

University of São Paulo, Brazil

Reviewed by:

Reynaldo Palacios-Bereche, Federal University of ABC, Brazil Karina Angelica Ojeda Delgado, University of Cartagena, Colombia

*Correspondence:

Pablo Silva Ortiz pabloaso@unicamp.br John Posada

j.a.posadaduque@tudelft.nI

Specialty section:

This article was submitted to Computational Methods in Chemical Engineering,

a section of the journal

Frontiers in Chemical Engineering

Received: 18 June 2021

Accepted: 30 August 2021

Published: 08 October 2021

Citation:

Silva Ortiz P, Maier $S$,

Dietrich R-U Pinto Mariano A, Maciel Filho $R$ and Posada J (2021) Comparative Techno-Economic and Exergetic Analysis of Circulating and

Dual Bed Biomass

Gasification Systems.

Front. Chem. Eng. 3:727068.

doi: 10.3389/fceng.2021.727068

\author{
Pablo Silva Ortiz ${ }^{1,2 *}$, Simon Maier ${ }^{3}$, Ralph-Uwe Dietrich ${ }^{3}$, Adriano Pinto Mariano ${ }^{1}$, \\ Rubens Maciel Filho ${ }^{1}$ and John Posada ${ }^{2 *}$
}

${ }^{1}$ Laboratory of Optimization, Design, and Advanced Control, School of Chemical Engineering, University of Campinas, Campinas, Brazil, ${ }^{2}$ Faculty of Applied Sciences, Department of Biotechnology, Delft University of Technology, Delft, Netherlands, ${ }^{3}$ German Aerospace Center, Institute of Engineering Thermodynamics, Stuttgart, Germany

In this work, the techno-economic and exergy analyses of two gasification technologies with integration into heat and power combined cycles are presented: i). Circulating fluidized bed (CFB) and ii). Dual fluidized bed (DFB) systems. As feedstock, lignocellulosic biomass (sugarcane bagasse, SCB) was considered. The gasification process of the fluidized-bed systems (circulating and dual bed) and the syngas conversion were performed using Aspen Plus ${ }^{\circledR}$ software. The process design includes biomass drying and gasification, syngas cleaning, combustion, power generation, and heat recovery. The SCB-DFB system has the lowest irreversibility rate and, as a result, the highest overall performance and power generation (achieving 32\% in the gasification system and 53\% of exergy efficiency when coupled with the combined cycle). From the techno-economic assessment, the SCB-DFB system has the lowest total production costs per unit of energy. Hence, the dual fluidized bed systems could be a more competitive technology for the agro-industrial sector to generate power from lignocellulosic materials.

Keywords: lignocellulosic gasification, techno-economic analysis, exergy analysis, process integration, gasification (biomass)

\section{INTRODUCTION}

Currently, the gasification process is one of the most studied thermochemical pathways to disrupt the lignocellulosic biomass into molecules that produce liquid fuels and power at low and high temperatures (Nogueira et al., 2011; Miranda et al., 2021). Thus, based on the broad availability of processed lignocellulosic biomass (i.e., sugarcane bagasse and straw) in the ethanol and sugar industry, including other agro-industrial activities, it represents a useful feedstock to be harnessed. In this context and searching for sustainable bioenergy systems insights, there is growing attention to

\footnotetext{
Abbreviations: DB, dry basis; B (MW), exergy flow rate; LHV (kJ/kg), lower heating value; $\mathrm{HHV}(\mathrm{kJ} / \mathrm{kg})$, higher heating value; $\mathrm{Nm} 3$, normal cubic meter; MWth, megawatt-hour thermal; MWe, megawatt electric; kWth, kilowatt-hour thermal; $\mathrm{b} \mathrm{kJ} / \mathrm{kg}$, specific flow exergy; WB, wet basis; CAPEX, capital expenditures or capital investment costs; CFB, circulating fluidized bed gasifier; DFB, dual fluidized bed gasifier; EC, equipment costs; FT, Fischer-Tropsch; FCI, fixed capital investment; LCM, lignocellulosic materials; NPC, net production costs; OPEX, operational expenditures; TEPET, techno-economic process evaluation tool; SCB, sugarcane bagasse; STB ratio, steam-to-biomass.
} 
the simultaneous use of lignocellulosic materials for the liquid biofuel production and power generation.

Recently, several comprehensive reviews have been published on biomass gasification involving the description of processes, trends, and technological issues. Asadullah (2014) reports on the limitations of biomass steps for the electricity generation. Furthermore, the author discusses the effects of operational parameters in the supply chain management, pretreatment, conversion, cleaning, and utilization steps using syngas for the power generation. Damartzis and Zabaniotou (2011) present the thermochemical conversion of biomass to second-generation biofuels and indicate the emerging challenges and opportunities for process integration schemes. Moreover, Gómez-Barea and Leckner (2010) analyzed the technical aspects of the biomass gasification modeling in fluidized bed gasifiers (i.e., bubbling and circulating) and Hanchate et al. (2021) offer a holistic view on the current research and developments of dual fluidized bed gasification systems for the syngas production. Safarian et al., 2019 collect and analyze statistics on the increasing number of gasification modeling studies and techniques. An extensive technical literature review of model adjustments has been carried out to offer a better understanding of gasification modeling for future research. For instance, Silva et al. (2019) provide an updated review of the stoichiometric thermodynamic equilibrium model for biomass gasification applications. Also, Mehrpooya and Khalili, 2018 investigate 23 biomass sources through the modeling and simulation of biomass gasification. The process operating performance was analyzed thermodynamically based on the Gibbs free energy minimization and the restricted equilibrium method. Rupesh et al. (2016) analyze the performance of several biomasses during gasification through the energy and exergy analysis. Thus, a quasi-equilibrium gasifier model was developed to simulate and compare the feasibility of different biomass sources. Hence, it is noted that the multi-reaction equilibrium approach is a standard method for a gasifier modeling of biomass and coal sources as reported in the literature (Worley and Yale 2012; Broer and Peterson 2019). For the particular case of sugarcane bagasse gasification, a recent analysis has shown the syngas evolution in terms of the global reaction mechanism, taking into account a semi-batch reactor operated in a steady flow of high-temperature steam at atmospheric pressure (Ahmed and Gupta 2012).

Studies focusing on the economic assessment of biomass gasification have also recently been published (Esmaili et al., 2016; Ptasinski 2016; Rahimi et al., 2020). For example, Rahimi et al. (2020) developed a comprehensive software program to simulate biomass gasification, which utilized an experimental setup to calibrate the simulation results with appropriate modeling coefficients. Thus, the sensitivity analysis shows that increasing the biomass moisture content will decrease carbon monoxide $(\mathrm{CO})$ and increase hydrogen $\left(\mathrm{H}_{2}\right)$ and methane $\left(\mathrm{CH}_{4}\right)$ relative compositions in the produced gas. The authors proposed a system that could save roughly 4 million $\mathrm{Nm}^{3}$ of natural gas per year, and the period of return of the project investment report was 6 years. Shahabuddin et al. (2020) summarize the recent technoeconomic analyses for advanced configurations of the thermochemical production of $\mathrm{H}_{2}$ from biomass and residual wastes. This review finds that the thermal efficiency is near $50 \%$. Also, the authors found that the levelized cost of hydrogen $(\mathrm{LCOH})$ from biomass varies between 2.3 and 5.2 \$Unites States dollar $2020 / \mathrm{kg}_{\mathrm{H} 2}$ at raw material processing scales of 10 $\mathrm{MW}_{\text {th }}$ to 2.8-3.4 \$Unites States dollar $\mathrm{r}_{2020} / \mathrm{kg} \mathrm{H}_{\mathrm{H}}$ at scales over $250 \mathrm{MW}_{\mathrm{th}}$.

Hence, a preliminary $\mathrm{LCOH}$ estimation from residual wastes is in the range of 1.4-4.8 \$Unites States dollar ${ }_{2020} / \mathrm{kg}_{\mathrm{H} 2}$, depending upon the wastegate fee and project scale (Shahabuddin et al., 2020). Hannula (2016) explores the potential to increase the biofuel output from a gasification-based biorefinery using an external $\mathrm{H}_{2}$ supply. The author found that the biofuel output could be increased by a factor of 2.6-3.1 for the gasoline $\left(\mathrm{C}_{8} \mathrm{H}_{18}\right)$ or methane $\left(\mathrm{CH}_{4}\right)$ production over reference configurations, respectively. The economic assessment shows that the average cost of low-carbon hydrogen below 2.6-3.2 \$Unites States dollar $_{2016} / \mathrm{kg}$ H2 becomes economically desirable over nonenhanced designs, depending on the process configuration. The study analyzed the use of multiple available wastes and residues in the European Union (EU;197 Mt/year, 2016) and its conversion to biofuels, which could replace up to $41-63 \%$ of the EU's road transport fuel market in 2030, depending on the process design selected. AlNouss et al. (2019) propose a polygeneration system that utilizes multiple feedstock sources to produce high-quality urea, methanol, Fischer-Tropsch (FT) liquids, and power to perform the economic, energy, and environmental analyses. The results show that methanol $\left(\mathrm{CH}_{3} \mathrm{OH}\right)$ processing is the most profitable process with a net profit of about $0.03 \mathrm{USD}_{2019} / \mathrm{kg}_{\mathrm{CH} 3 \mathrm{OH}}$ of biomass input; when considering the production capacity, the liquid fuel production achieves net profits, roughly about $0.27 \mathrm{USD}_{2019} / \mathrm{kg}$ of product. A techno-economic study of forest biomass blends gasification for small-scale power production facilities in the Azores (Portugal) is presented by Sousa Cardoso et al. (2020). Experimental gasification tests in a $250 \mathrm{~kW}_{\text {th }}$ quasi-industrial biomass gasifier in a pilot-scale fluidized bed reactor validated the model. The results show the net present value (NPV), internal rate of return (IRR), and payback period (PBP) followed by a sensitivity analysis via Monte Carlo simulation for two distinct application sizes (100 and 1,000 kW). The $1,000 \mathrm{~kW}$ unit showed to be economically viable with an NPV of $486 \mathrm{k} €_{2020}$, IRR of $17.44 \%$, and PBP of 7.4 years. Heinze et al. (2019) carried out a techno-economic assessment of polygeneration based on the fluidized bed gasification. A $350 \mathrm{MW}_{\mathrm{e}}$ combined cycle power plant with a dryer, a fluidized bed gasifier, a gas purification unit, a CO-Shift system, and a Rectisol acid gas removal is shown in this process model. As a result, the model is being used to investigate the specific $\mathrm{CO}_{2}$ emissions and efficiency output for power and methanol production operation modes. Weiland and White (2018) perform a techno-economic analysis of an integrated gasification direct-fired supercritical $\left(\mathrm{sCO}_{2}\right)$ power cycle via a coal-fueled, oxy-fired direct $\mathrm{sCO}_{2}$ system, which is inherently amenable to carbon capture and storage (CCS) processes. The conceptual designs included a baseline $\mathrm{sCO}_{2}$ plant and an improved thermal integration between the $\mathrm{sCO}_{2}$ cycle and the gasifier. The outcomes show a 
cost of electricity (COE) of $137.3 \$ \mathrm{USD}_{2018} / \mathrm{MW}_{\mathrm{h}}$ and 122.7 $\$ \mathrm{USD}_{2018} / / \mathrm{MW}_{\mathrm{h}}$ for the baseline and thermally integrated $\mathrm{sCO}_{2}$ plants, respectively.

Recent developments on the valorization of biomass to valueadded commodities provide insights into the multidimensional drivers of biorefinery-derived platforms. For instance, Molino et al. (2018) include an overview of the technologies for converting biomass into syngas using gasification techniques (i.e., fixed bed reactors, fluidized bed reactors, and entrained flow reactors), the raw material characteristics, and the operating parameters. Kim et al. (2020) propose an integrated biorefinery strategy for coproducing liquid transportation fuels and high value-added chemicals from lignocellulosic biofuels. Niu et al. (2021) also proposed a novel biomass integrated gasification combined cycle (BIGCC) configuration, which featured an innovative two-stage enriched air gasification system coupling a fluidized bed via the Aspen Plus model. On the other hand, Patuzzi et al. (2021) compiled an extended set of data related to an overview of the reference values for the ranges of operation of small-scale biomass gasification systems available in the European market. Pregger et al. (2020) give an overview of the Future Fuels project lead by the German Aerospace Center (DLR) on producing and using synthetic fuels for electricity, space, transportation, and aviation sectors. However, although the lignocellulosic feedstock is considered to be accessible at a reduced cost, several technological options for their conversion are still under development. Note that the demonstration and commercial plants are still concentrated on power generation even though today's trend focuses on biofuels and high-value products as given in technology readiness level (TRL) reports by the International Renewable Energy Agency, IRENA (International Renewable Energy Agency, 2016), and the Delivering the United Kingdom's Future Energy Technologies (Energy Technologies Institute 2020), where Fischer-Tropsch (FT), synthetic natural gas (SNG), circulating fluidized bed $(\mathrm{CFB})$, and bubbling fluidized bed (BFB) were identified as promising and viable technologies.

It must be underlined that the gasification process is a significantly flexible process regarding feedstocks (i.e., lignocellulosic biomass) use, particularly in tropical zones (e.g., Brazil), in which the biomass production occurs throughout the entire season. Thus, these materials could be processed either to produce biofuels or to cogenerate electricity and heat on demand. Therefore, the flexibility aspects related to the gasification process (i.e., feedstock, conversion, and final use) options drive research and development opportunities for thermochemical pathways. Hence, this work aims to analyze and compare the technical, economic, and energy feasibility of two biomass gasification systems for the power generation. In this context, a biomass gasification model was developed to assess the technical, economic, and energy feasibility for the power production. Moreover, a performance-based comparison in terms of economic indicators (i.e., CAPEX, OPEX, and NPC) and technical metrics (i.e., exergy efficiency and irreversibilities rate) of the fluidized bed gasification technologies, also with the combined cycle integrated is carried out. The comparative analysis of the lignocellulosic biomass gasification systems using the exergy and techno-economic assessment as metrics is relevant to support a diversification strategy for an energy matrix development.

\section{MATERIALS AND METHODS}

First, the choice of suitable raw materials capable of producing gaseous fuels is presented (feedstock section). Next, the conversion technologies of the fluidized bed gasifiers are introduced. Later, the models used for the techno-economic analysis and the exergy assessment are provided.

\section{Feedstock}

The modeled thermochemical systems include agroforestry residues feedstocks (Table 1) produced in Brazil. For instance, the Brazilian sugarcane industry processed around 643 million tons of cane in the 2019/2020 season (EPE 2019). Thus, after the extraction of the juice (sucrose) from sugarcane stalks, the sugarcane bagasse (SCB) is obtained. On an average, one tonne of crushed cane generates about $250 \mathrm{~kg}$ of bagasse $(50 \%$ moisture). In this context, data for the autonomous distillery with the processing of 4 million tons of sugarcane (TC) per season were considered, which represent a typical crushing capacity in the São Paulo State, Brazil. Thus, the biomass gasification process simulation is explored and analyzed using the sugarcane bagasse (SCB) available after cleaning and crushing the stalks, roughly 125 dry tonnes of biomass per hour.

\section{Conversion Technologies}

In this work, a promising thermochemical pathway was considered in the technological assessment. Fluidized bed gasifiers are known for their temperature consistency, larger efficiency, and performance mixing. Thus, two fluidized bed types were evaluated, circulating and dual bed systems. Essentially, the fluidized bed technology comprises granular solids (bed materials) that are kept semi-suspended (fluidized condition) by injecting the gasifying medium through the solid particles. This type of gasifier is relatively insensitive to the quality of the fuel due to its excellent gas-solid mixing and large thermal inertia of the fluidized bed (Basu 2018). The temperature uniformity around this gasifier significantly decreases the possibility of fuel agglomeration. This design has proven to be beneficial for the biomass gasification. It produces tar at a rate comparable to updraft configurations, roughly $50 \mathrm{~g} / \mathrm{Nm}^{3}$ (Basu 2018).

Fluidized bed systems are known to achieve higher efficiencies when compared to other types of gasifiers. Nevertheless, they are still an immature technology for the electricity generation due to high capital and operational costs, as well as maintenance costs and expensive control systems, which limits their development (Anukam et al., 2016). Facing these challenges, detailed simulation models were carried out to determine the technical performance and economic assessment of these fluidized bed systems (CFB model and DFB model) based on a study by Nikoo and Mahinpey (2008), Camacho-ardila et al., 2012, and Medeiros et al. (2017). The synthesis of the performance conditions of the 
TABLE 1 | Feedstock composition.

Biomass type

Proximate analysis (d.b.)

Volatile Matter (\%) 82.97

Fixed Carbon (\%) 11.81

Ash (\%) 5.22

Moisture content (\%) 50
Sugarcane bagasse (SCB)

Ultimate analysis (d.b.)

Carbon (\%) 44.52

Hydrogen (\%) 5.9

Oxygen (\%) 43.65

Nitrogen (\%) 0.32

Sulfur (\%) 0.1

Chlorine (\%) 0.29

Reference:Camacho-ardila et al. (2012)

*Heating and exergy values were determined using the correlation given in abbreviations of the Supplementary Materials S5, S6.

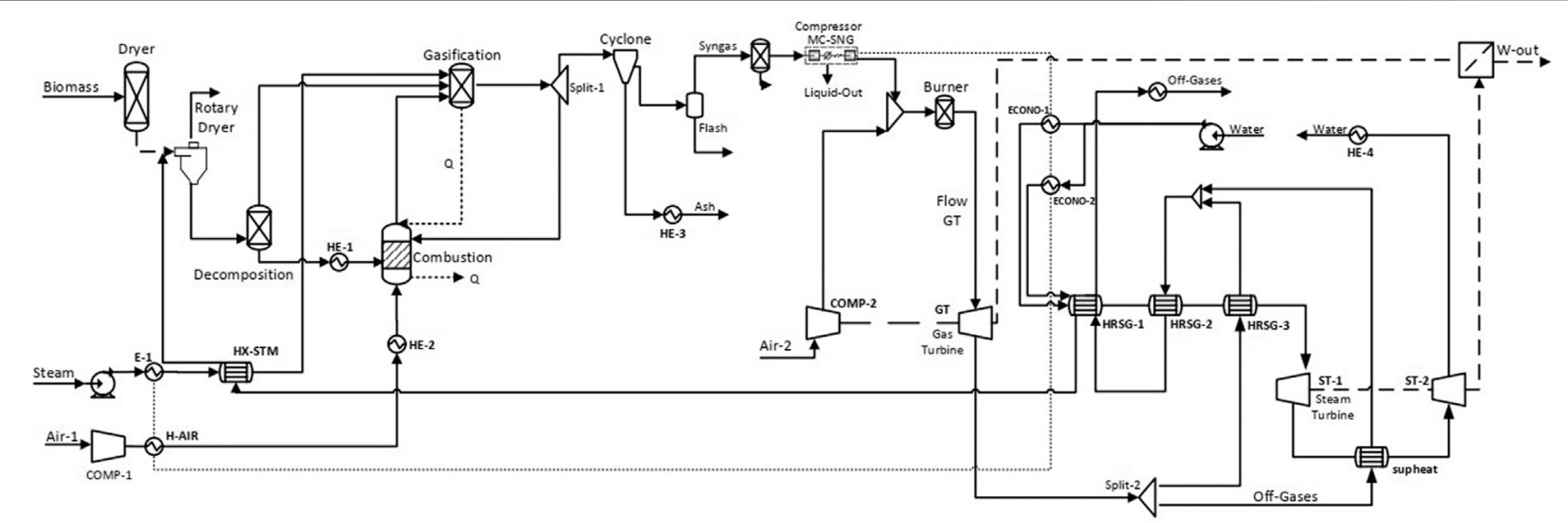

FIGURE 1 | Circulating fluidized bed model.

gasification processes can be found in Supplementary Tables S1, S2 (Supplemental material, SM).

\section{Circulating Fluidized Bed (CFB Model)}

Figure 1 shows the atmospheric circulating fluidized bed system integrated with the combined cycle. The first phase is related to the feed handling and preparation, and the modeled biomass feedstock has an ultimate and proximate analysis shown in Table 1. In this stage, a directly heated single-pass rotary dryer is included in the system to deal with the moisture content of the raw material. It allows hot gases to be in contact with the biomass material inside a rotating drum before feeding into the decomposition reactor. Next, biomass decomposition occurs, which involves a yield reactor converting biomass into its constituent components such as carbon, hydrogen, oxygen, nitrogen, sulfur, chlorine, and ash. Later, the resulting stream (Ryield block and decomposition) goes through a combustion zone (bed); at this point, the pyrolysis is followed by the gasification process (gasification zone). The gasifying agent (air) is delivered at the next stage (char gasification) to ensure optimal gasification operational conditions. Besides, both the remaining carbon fraction and ash make up the char particles produced by the devolatilization process. Furthermore, at the riser outlet, the cyclone model (cyclone unit) reflects the gas/solid separation stage. All of the gases from the Gibbs reactor make up the top outlet flow (syngas). Last, the output from the ashes is represented by the bottom outlet solid stream (ash).

The assumptions adopted during the gasification process simulation were $i$ ) steady-state and isothermal conditions; ii) the devolatilization step is considered instantaneous and occurs at the bottom of the bed (very short time required for volatile combustion); iii) char and volatiles are formed in the pyrolysis stage. Non-condensable volatiles (e.g., $\mathrm{H}_{2}, \mathrm{CO}, \mathrm{CO}_{2}, \mathrm{CH}_{4}$, and $\mathrm{C}_{2} \mathrm{H}_{2}$ ), condensable volatiles (tar), and water are among the volatiles considered (Gómez-Barea and Leckner 2010); and iv) only carbon and ash are found in char (Nikoo and Mahinpey 2008).

\section{Dual Fluidized Bed (DFB Model)}

The dual fluidized bed was modeled as indicated in Figure 2. The model includes processing and drying of biomass feed, indirect heating gasification in a dual-circulating fluidized bed, and cyclone removal of particles. This type of gasifier consists of two independent and interconnected beds through which the hot bed material circulates and transfers heat between different regions. In the gasification zone (RGibbs model), steam is used as the only gasification agent. In contrast, in the 


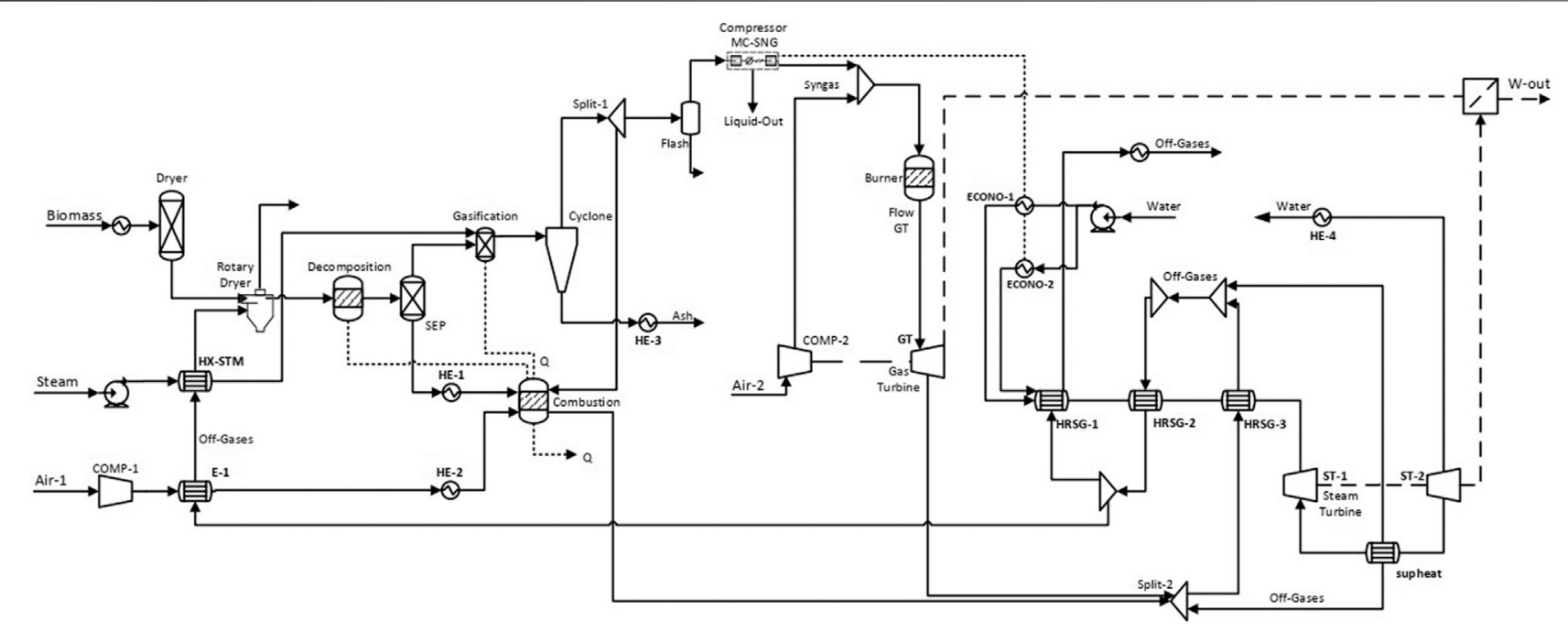

FIGURE 2 | Dual fluidized bed model.

combustion zone (RStoic model), air is bubbled as a combustion agent. Thus, a high-quality syngas can be produced with a higher $\mathrm{H}_{2}$ concentration (Corella et al., 2007).

Since nonconventional components are excluded from the phase and chemical equilibrium calculations, a decomposition block (RYield reactor) breaks down biomass into its constituent elements $\left(\mathrm{C}, \mathrm{H}_{2}, \mathrm{O}_{2}, \mathrm{~N}_{2}, \mathrm{Cl}, \mathrm{S}\right.$, and $\left.\mathrm{H}_{2} \mathrm{O}\right)$, allowing the subsequent stages. Later, preheated air at $130^{\circ} \mathrm{C}$ is supplied into the combustion zone, where char is burned to supply heat for the endothermic process.

The separator, on the other hand, denotes the separation of the char fraction utilized for combustion. At 2.5 bar $\left(130^{\circ} \mathrm{C}\right)$, the gasification zone is supplied with biomass and saturated steam, which works as a gasifying agent. The steam-to-biomass (STB ratio) adopted was 0.34 with lower value preference (typical STB range between 0.2 and 2) as a consequence of lower energy consumption (Silva and Rouboa, 2014). The gasification and the combustion zone temperatures were $950^{\circ} \mathrm{C}$ and $1,000^{\circ} \mathrm{C}$, respectively, which is consistent with their operating parameters (Worley and Yale 2012; Broer and Peterson 2019). Afterward, the gas passes by a cyclone to remove particulates. It is emphasized that the dual gasifier model assumes a multi-reaction equilibrium approach.

\section{Combined Cycle}

The combined cycle comprises a gas turbine that simulates a Brayton cycle and a steam turbine following a conventional Rankine cycle. The simulation was carried out focusing on the following assumptions: i). Steady-state operation; ii). isentropic compression process, and iii). No heat losses in the combustion chamber. It is essential to mention that the process flowsheets of the gasification system integrated with the combined cycle are given in Figures 1, 2, respectively. The inlet stream in the combined cycle is the cleaned synthetic gas (syngas) produced in the gasification process after being passed by the MC-SNG compressor; this equipment represents a multistage compression (centrifugal-rotary) with intercooling stages at $40^{\circ} \mathrm{C}$ and condensation flash drums. On the other hand, the mass flow rate of air is set to obtain a total outlet flow rate and compressed according to the specified pressure ratio of 20 bar. Thus, the mass flow rate of the air inlet to the gas turbine is calculated to achieve an exiting temperature of $1,350^{\circ} \mathrm{C}$ in the outlet stream. A design spec was used to vary the oxygen inlet until the combustion is complete. After compression, the air is led into the combustion chamber of the gas turbine (RStoic block). By combusting the syngas, the flue gas, together with the excess air stream is heated up to $1,350^{\circ} \mathrm{C}$ before entering the gas turbine (GT). The GT operates with an outlet pressure of $1.1 \mathrm{bar}$ and an isentropic efficiency of $88 \%$.

Next, the outlet gases from the GT enter into the heat recovery steam generator (HRSG) section, in which it exchanges heat with a steam cycle. The steam cycle consists of one high-pressure steam turbine (ST) and one medium- to low-pressure steam turbine. The steam enters the high-pressure steam turbine at 200 bar and $550^{\circ} \mathrm{C}$ and exits at 50 bar. After an intermediate superheating step, the steam is led into the second ST and expands until a pressure of 0.05 bar and a condensate fraction of $5 \%$. A heat exchanger is utilized to condense the water that is recirculated. The synthesis of the parameters adopted in the combined cycle can be seen in Supplementary Tables S3, S4. More details of the technical performance of gas turbines using a low heating value fuel can be found elsewhere (Silva et al., 2013; Zornek et al., 2015).

\section{Heat Integration}

The heat integration was performed according to the pinch point analysis. The flue gas stream of the gas turbine is primarily used to generate steam for the steam turbines, while part of it is preheating the required steam and air streams that lead into the gasifier. Additionally, a part of the flue gas is used in a drying unit. In the case of the DFB gasification concept, the flue gas exits the last heat exchanger within the combined cycle loop at $291^{\circ} \mathrm{C}$. 
TABLE 2 | Comparison results of selected parameters.

\begin{tabular}{lccc}
\hline Parameters & Units & SCB DFB & SCB CFB \\
\hline $\begin{array}{l}\text { Higher heating value of Syngas } \\
\quad\end{array}$ & $\mathrm{kJ} / \mathrm{kg}$ & 17,090 & \\
$\begin{array}{l}\mathrm{HHV} \mathrm{V}_{\text {syngas }} \\
\text { Syngas Composition }\end{array}$ & $\% \mathrm{vol}$ & 56.8 & 5,291 \\
$\quad$ Hydrogen, $\mathrm{H}_{2}$ & $\% \mathrm{vol}$ & 27.2 & 26.3 \\
$\quad$ Carbon Monoxide, $\mathrm{CO}$ & $\% \mathrm{vol}$ & 13.4 & 15.3 \\
$\quad$ Carbon dioxide, $\mathrm{CO}_{2}$ & $\% \mathrm{vol}$ & 2.4 & 15.5 \\
$\quad$ Methane, $\mathrm{CH}_{4}$ & $\%$ vol & 0.2 & 2.3 \\
$\quad$ Nitrogen, $\mathrm{N}_{2}$ & & & 40.6 \\
Exergy of Syngas & $\mathrm{MW}$ & 198.5 & 223.5 \\
$\quad$ Exergy flow rate & & & \\
\hline
\end{tabular}

Its remaining sensible heat is utilized as follows: $3.2 \mathrm{MW}_{\text {th }}$ is used for air preheating while $14.8 \mathrm{MW}_{\text {th }}$ is utilized for the gasification steam generation. Finally, the drying unit consumes $36.1 \mathrm{MW}_{\text {th }}$ to reduce the moisture content from 50 to $10 \mathrm{wt} . \%$. To prevent condensation, the flue gas exits the drying unit at $65^{\circ} \mathrm{C}$. The intercooling stages in between the syngas compression provide in the case of DFB gasification a low-temperature heat of $7.5 \mathrm{MW}_{\text {th }}$ which is used to preheat the water of the combined cycle loop from 21 to $72^{\circ} \mathrm{C}$.

Due to the much higher volume flow in the CFB gasification system, the heat integration concept is slightly modified. The syngas compression step requires $17.0 \mathrm{MW}_{\text {th }}$ of cooling between 175 and $40^{\circ} \mathrm{C}$, which cannot be fully provided by the combined cycle water which is thereby heated from 21 to $150^{\circ} \mathrm{C}\left(12.9 \mathrm{MW}_{\mathrm{th}}\right)$. The available intercooling heat is also used to preheat the air for the gasification $\left(2.1 \mathrm{MW}_{\text {th }}\right)$, as well as to increase the water temperature for gasification from 20 to $105^{\circ} \mathrm{C}\left(2.0 \mathrm{MW}_{\mathrm{th}}\right)$. The flue gas stream exits the last heat exchanger of the combined cycle at $326^{\circ} \mathrm{C}$ even though some of the required heat for air and steam preparation can be provided by the intercooling sections. Exchanging the remaining $12.8 \mathrm{MW}_{\text {th }}$ of heat to generate the steam for the gasifier, the flue gas enters the drying unit at $266^{\circ} \mathrm{C}$ and exits it at $70^{\circ} \mathrm{C}$ due to its higher partial pressure water.

\section{Techno-Economic Evaluation}

The TEPET (Techno-Economic Process Evaluation Tool) methodology was used for estimating capital investment costs or capital expenditures (CAPEX), operational expenditures (OPEX), and net production costs (NPC). The cost estimation is expected to have an accuracy of $\pm 30 \%$ for well-known chemical processes (Albrecht et al., 2017), according to classes three and four of the classification system of the Association for the Advancement of Cost Engineering (AACE International, 2011).

Fixed capital investment (FCI), which includes equipment costs (EC) and additional capital requirements throughout the building phase, is included in CAPEX. TEPET is used to determine EC for all installed units based mainly on Peters et al. (2003). Besides, the TEPET was used to create a database with cost functions for chemical processes and fuel synthesis equipment.

On the other hand, the OPEX could be broken down into costs for feedstocks and utilities and additional indirect operational costs (e.g., maintenance, labor, insurances, administration, and taxes). Due to the difficulty of predicting exact prices, conventional estimates based on historical data from the chemical process sector are employed (Peters et al., 2003).

The TEPET methodology description is given in a study by Albrecht et al. (2017). The equipment costs correlations used and the expression to calculate the new sized equipment are displayed in Materials and Methods-SI. In this study, an operating time of the plant of 20 years, an interest rate of $7 \%$, and an annual full load of 8,000 h were considered. Another aspect to be highlighted in the techno-economic analysis is the raw material logistic (i.e., availability, transportation, cost production, and storage). In this context, Brazil is characterized by seasonal availability and low-cost biomass. Hence, a representative market price for the season 2018-2019 was used, corresponding to $25 € / t$ biomass (Watanabe et al., 2020).

\section{Exergy Assessment}

The value and usefulness of resources are related to their capacity to do useful work. The second law of thermodynamics accounts for the fact, even though under ideal conditions, heat cannot be entirely converted into work. Thus, the concept of exergy represents the maximum ability of a system to do work concerning a reference state (Bakshi, 2019). The technological scenarios are based on the calculation of the steady-state mass, energy, and exergy balances, according to Eqs 1-3, respectively, for each one of the control volumes.

$$
\begin{gathered}
\sum_{\text {inlet }} \dot{m}_{i}=\sum_{\text {outlet }} \dot{m}_{e} \\
\sum_{\text {inlet }} \dot{m}_{i} h_{i}+\dot{Q}_{C V}=\sum_{\text {outlet }} \dot{m}_{e} h_{e}+\dot{W}_{C V}, \\
\sum_{\text {inlet }} \dot{m}_{i} b_{i}+\dot{Q}_{C V_{i}}\left(1-\frac{T o}{T}\right)=\sum_{\text {outlet }} \dot{m}_{e} b_{e}+\dot{W}_{C V_{e}}+\dot{I},
\end{gathered}
$$

where $\sum \dot{m}_{i} b_{i}$ represents the exergy of the process inputs $\left(\dot{B}_{\text {inputs }}\right)^{\text {inlet }} \sum_{\text {outlet }} \dot{m}_{e} b_{e}$ the exergy of the process output $\left(\dot{B}_{\text {products }}\right)$, and $(\dot{I})$ the irreversibility (exergy losses). In this work, the chemical $\left(b_{\mathrm{CH}}\right)$ and physical $\left(\mathrm{b}_{\mathrm{PH}}\right)$ exergies are measured due to the physicochemical processes involved. Thus, $b_{\mathrm{PH}}$ was determined according to Eq. 4.

$$
\dot{B}_{P H}=H-H_{0}-T_{0}\left(S-S_{0}\right),
$$

where $H$ (in $\mathrm{kW}$ ) is the enthalpy flow rate at $\mathrm{P}$ and $\mathrm{T}$; $S$ (in $\mathrm{kW} / \mathrm{K}$ ) denotes the entropy rate/flow rate at $\mathrm{P}$ and $\mathrm{T}$; $T_{o}$ (in $\mathrm{K}$ ) is the temperature at the reference state; $H_{o}$ (in $\mathrm{kW}$ ) represents the enthalpy flow rate at $\mathrm{P}_{\mathrm{o}}$ and $\mathrm{T}_{\mathrm{o}}$; and $S_{o}$ (in $\mathrm{kW} / \mathrm{K}$ ) is the entropy rate evaluated at $\mathrm{P}_{\mathrm{o}}$ and $\mathrm{T}_{\mathrm{o}}$. In particular, the most significant contribution of natural resources, including lignocellulosic biomass, are included in the $b_{\mathrm{CH}}$ term (chemical exergy value) (Ofori-Boateng, 2013). Conceptually, it estimates the value of a chemical substance in comparison to a predetermined reference environment (Marais et al., 2017). Eq. 5 defines the chemical exergy for a mixture:

$$
\dot{B}_{C H}=\mathrm{n}_{m i x}\left[\sum_{i} x_{i} b_{i}^{c h}+R_{u} T_{0} \sum_{i} x_{i} \ln r_{i} x_{i}\right],
$$



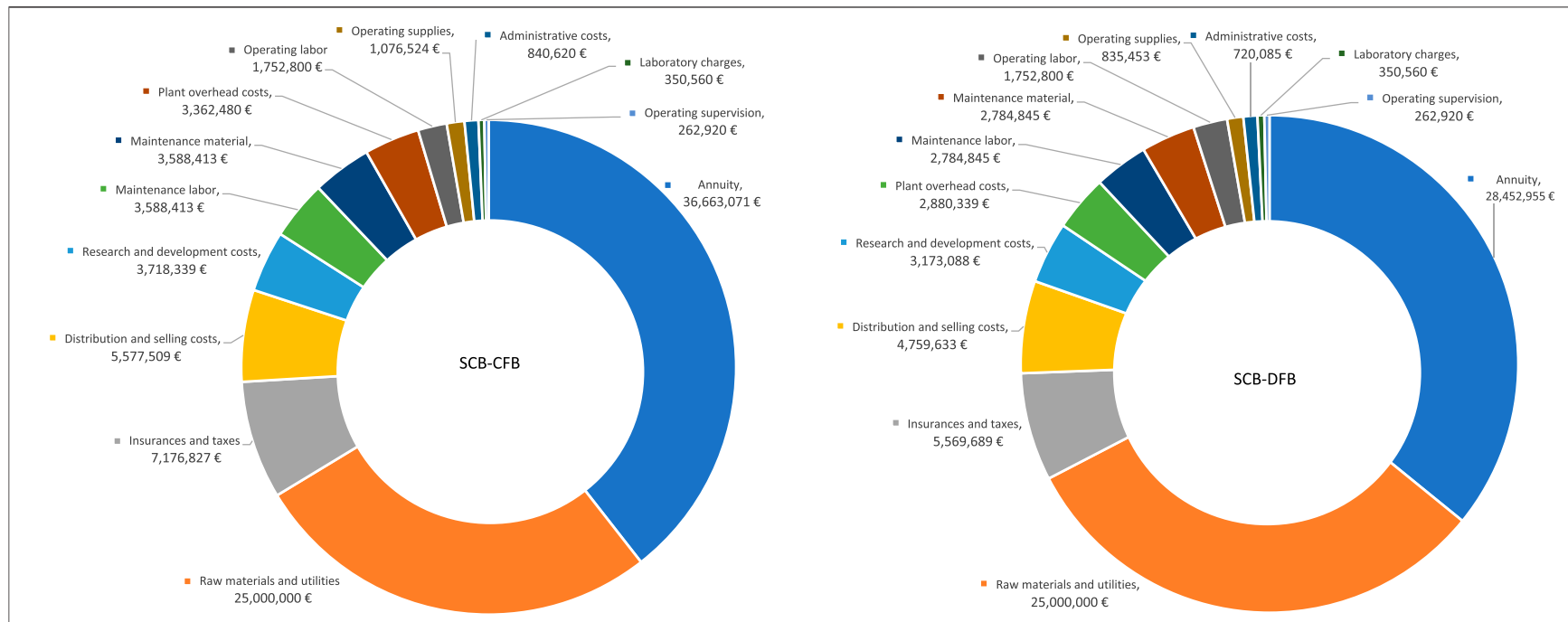

FIGURE 3 | Total production costs of the systems.

where $n_{\text {mix }}$ is the total amount of moles of all constituents in a mixture and $x_{i}$ is the mole fraction of component $i$. The influence of ' $Y$ was evaluated for each compound, thereby allowing the observation that it offers values close to 1 (as given in S6). Consequently, ' $\mathrm{Y}$ was assumed to be equal to 1 , an ideal solution, in mixtures for the $b_{\mathrm{CH}}$ calculation (Silva Ortiz and de Oliveira, 2014). The $b_{i}^{c h}$ term denoted the standard chemical exergy. The chemical exergies for conventional compounds are found in the Szargut et al., 1988 and Kotas (1985). The correlation related to the $\mathrm{b}_{\mathrm{CH}}$ calculations of the nonconventional components is given in Supplementary Equation S6. Furthermore, the expressions to calculate the lower heating value (LHV) and the higher heating value (HHV) are presented in abbreviations-SM.

\section{Performance Analysis of the Systems}

A set of complementary performance indicators were selected for the thermochemical pathways based on the thermodynamic and techno-economic assessment. These metrics are suitable for system comparisons and identification of promising alternatives focus on the process integration of the configurations. Initially, the exergy efficiency and irreversibility rate were used as indexes to assess the technical performance of the plants. Meanwhile, key financial indicators were adopted to evaluate the technoeconomic parameters (i.e., the fixed capital investment-FCI, the total capital investment-TCI, capital expense-CAPEX, operating expense-OPEX, and net production costs-NPC), as shown in Techno-economic analysis.

Exergy efficiency: It was determined by the ratio between the exergy of the products and the exergy of the resources, as given in Eq. 6.

$$
\eta_{B}=\frac{\sum \dot{\mathrm{B}}_{\text {products }}}{\sum \dot{\mathrm{B}}_{\text {resources }}} .
$$

Irreversibility rate: The irreversibility metric was obtained by applying the exergy balance expression introduced in Eq. 3 .

\section{RESULTS AND DISCUSSION}

\section{Simulation Analysis}

Initially, Table 2 presents the selected parameters of the biomass and syngas composition for each configuration. These data were used to determine the global performance assessment of the systems. In general, the content of hydrocarbons in the syngas composition, such as methane was minimum, which may be related to the full cracking reaction under high-temperature conditions (Table. 2). This tendency matched the experimental results for fluidized bed gasifiers published by Molino et al. (2018) and Camacho-ardila., et al. (2012) for a pilot-scale simple and two-stage enriched air gasification process.

The results of the combined cycle can be compared with various previous studies. For example, Emun et al. (2010) analyzed different operation strategies of an integrated gasification combined cycle (IGCC) plant and obtained an exergy efficiency of $\eta=45 \%$. Liu and Karimi (2018) reported the efficiency in the combined cycle of $56.3 \%$ using natural gas as a fuel. In the SCB-DFB system, an exergy efficiency of $\eta=54 \%$ was achieved within the combined cycle section. The synthesis of the results obtained in the combined cycle performance is given in Supplementary Table S4.

\section{Techno-Economic Analysis}

Figure 3 shows the total production costs estimated for each configuration. These graphical representations indicated the cost contribution of the electricity generation in all scenarios by each process step. For instance, the annualized capital cost represented the highest participation in the production costs. This term was calculated using the relation between the annuity factor, the fixed capital investment (FCI), the total capital investment (TCI), and 
TABLE 3 | Techno-economic assessment evaluation.

Biomass type

Type of gasifier

Equipment costs (EC)

Direct capital costs (DCC)

Indirect capital costs (ICC)

Fixed capital investment ( $\mathrm{FCl})$

Total capital investment (TCl)

Annuity (annualized CAPEX)

OPEX

Product output (PO)

Net production costs (NPC)

Specific net production costs
SCB-DFB

Sugarcane bagasse

Fluidized bed

102,785

203,302

37,661

278,484

309,427

28,452

50,874

860,288

79,327

0.09
SCB-CFB

Sugarcane bagasse Circulating

119,703

262,380

49,371

358,841

398,712

36,663

56,295

783,323

92,958

0.12

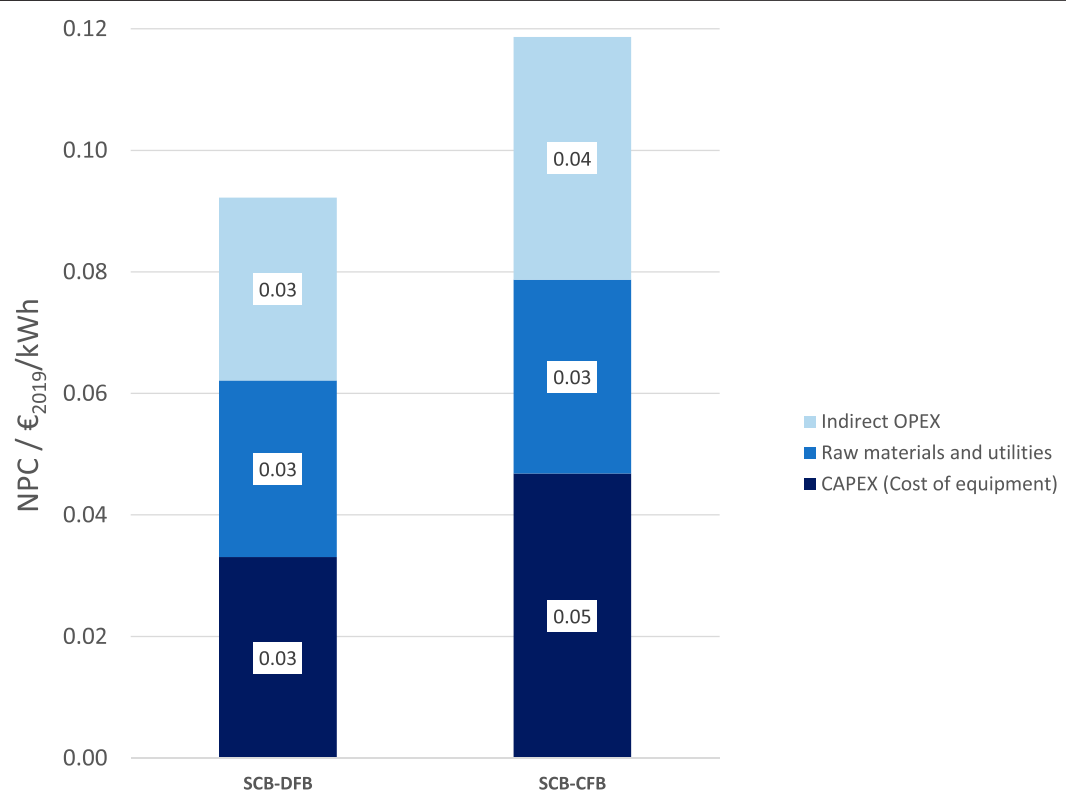

FIGURE 4 | NPC Breakdown of the system configurations.

the interest rate, as indicated in a study by Albrecht et al. (2017), using 2019 as the year of reference in the analysis. Figures 3A,B present the techno-economic outcomes concerning the dual fluidized bed (DFB) and the circulating fluidized-bed (CFB) using sugarcane bagasse as a feedstock integrated into the combined cycle, respectively.

In addition, Table 3 displays the economic analysis results for each configuration obtained through the TEPET (TechnoEconomic Process Evaluation Tool) evaluation. Thus, a breakdown of the investment and operational costs is given to determine the global behavior of the system in light of the technoeconomic feasibility assessment. It must be underlined that the TCI term represents the CAPEX (capital expenditures) of the thermochemical routes. Besides, OPEX and NPC are specified in this table.

According to Table 3, the SCB-CFB model represents the higher total cost of investment when compared to the dual fluidized bed systems, which is associated with the equipment costs and fixed capital investment. It is emphasized that the specific net production cost of the SCB-CFB system was the highest. In contrast, the SCBDFB model presents the most attractive product output per year among the integrated gasification combined cycle.

In light of these results, the Lang factor was considered individually for each system to reflect the other costs contribution to plant cost. Lang factor is defined as the ratio of total capital investment (TCI) to delivered-to-site equipment cost (EC), given in Table 3. For all the systems, the Lang Factor was calculated (SCB-DFB 2.7 and SCB-CFB 3.0), which is a typical value for mixed fluids-solids processing plants (Peters et al., 2003). For instance, the Lang Factor for the production costs of syngas from lignocellulosic biomass in Brazil was determined as 3.8 through a biomass supply configuration focus on bulk chemicals (Benalcázar et al., 2017). 


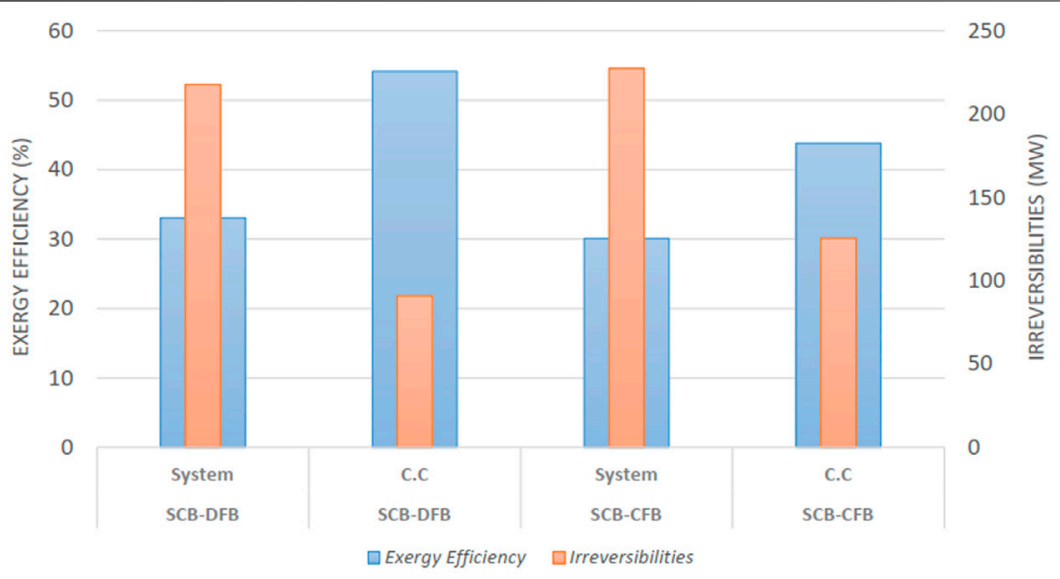

System: It comprises only the gasification process

C.C: It refers to the combined cycle

FIGURE 5 | System performance of the thermochemical routes.

TABLE 4 | Key stream parameters.

Parameters

Mass flow (kg/hr)

110,230

529,467

698,793

125,000

196,553

SYN Gas

DFB process

Air-1

Air-2

Flow GT

Biomass

SYN Gas
168,001

617,105

664,627

125,000

81,012
Temp. (C)

Pressure (bar)

Exergy (MW)

25
20
1,350
25
900

25
20
1,350
25
950

1.5

7.1

264.2

325.4

223.4

2.3

8.3

247.9

325.4

198.1
Moreover, the payback period, which denotes the amount of time it takes to recover the investment cost, was determined for each system (SCB-DFB 5.4 and SCB-CFB 7.6 years, respectively). The results show that the SCB-DFB model offers a shorter payback period. Thus, this configuration could represent the more attractive investment under this indicator and also could represent a lower risk of the project. Furthermore, the specific net production cost of the electricity via dual fluidized bed systems (SCB-DFB, $0.09 €_{2019}$ / $\mathrm{kWh}$ and SCB-CFB, $0.12 €_{2019} / \mathrm{kWh}$ ) could be competitive within the Brazilian market (Figure 4), and when compared with the coal power plants $\left(0.16 €_{2019} / \mathrm{kWh}\right)$ and nuclear systems $\left(0.25 €_{2019} / \mathrm{kWh}\right)$ (EPE, 2019).

\section{Performance Assessment}

To synthesize the impact of the coupled systems (gasification and power generation) in terms of the performance indicators

In general, the heating value (LHV and HHV) of syngas is a function of the equivalence ratio and their chemical composition (Table 2). Thus, the gasification section is a crucial issue related to optimizing the global biomass integrated gasification combined cycle (BIGCC) performance based on the process integration strategy adopted.

Accordingly, the SCB-DFB model (dual fluidized bed using bagasse) shows a higher exergetic efficiency as a consequence of the lower irreversibilities of the overall systems, when compared with the models integrated with the gasification process and the combined cycle (Figure 5). Hence, the SCBDFB model represents the best operating conditions to maximize the exergy efficiency of this system by maximizing heat recovery. In general, the key factors concerning the thermodynamic optimization of the systems are focused on setting the optimal performance conditions, such as the excess air fraction that exists in the combustion, the air inlet temperature, the air-fuel ratio, and preheating the combustion air. Last, the main stream parameters of the CFB and DFB processes are specified in Table 4. 


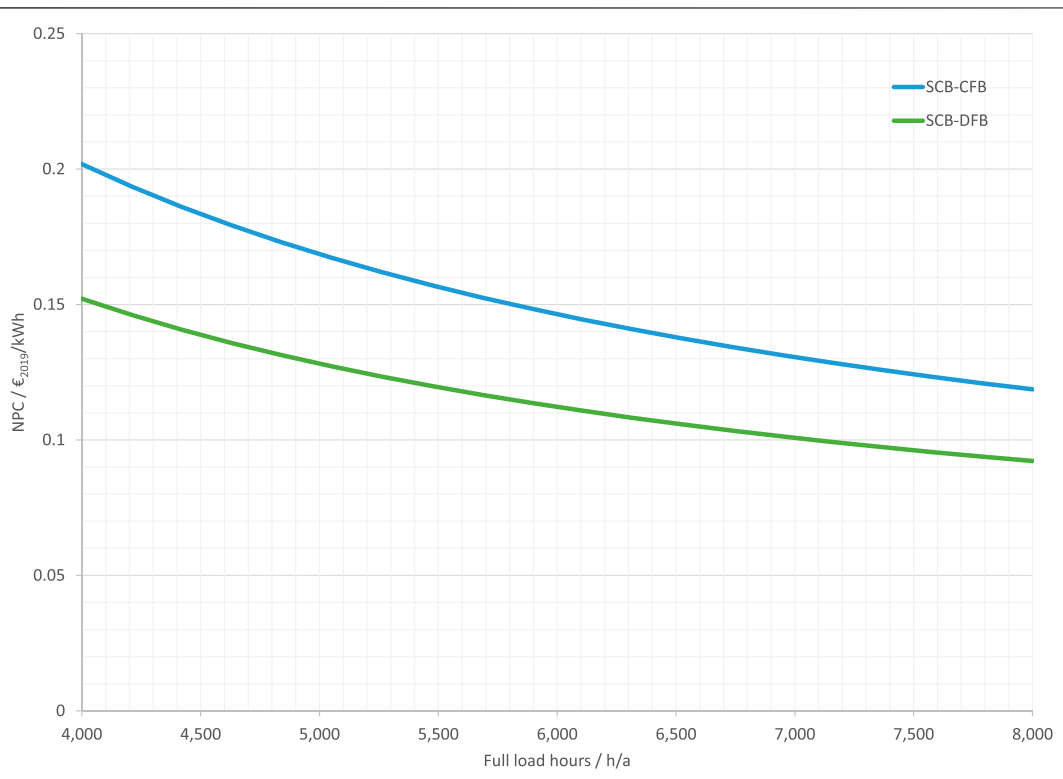

FIGURE 6 | Effect of the operation time on the specific net production costs.

\section{Sensitivity Analysis}

The impact of the operation time on the specific net production costs $(N P C, € / \mathrm{kWh})$ was explored in Figure 6 taking into account the full load hours per year for each system. Furthermore, a sensitivity analysis for the best configuration ranking based on the economic and exergy results and the effects of varying the compressor pressure ratio for the SCB-DFB case is given in References-SM (Supplementary Figure S3 and Supplementary Table S9).

In addition, the exergy flows associated with each process configuration (gasification system and combined cycle) are presented in Grassmann diagrams (Supplementary Figures S1, S2 in the Supplementary Material). Last, the energy potential of the syngas conversion to synthetic fuels via the FT synthesis was determined to analyze and compare this process alternative with other promising technological pathways reported by Albrecht et al. (2017). This comparison did not ignore the fact that the $\mathrm{H}_{2} / \mathrm{CO}$ ratio in the syngas in the present study is lower than that in the referred study. Furthermore, Albrecht et al. (2017) considered that the overall hydrogen conversion was $90 \%$, and the CO conversion was calculated accordingly. Since $25 \mathrm{wt} . \%$ of the FT products leave the reactor in the gaseous state, the energy losses (difference between the energy of syngas and energy of FT products) were $102 \mathrm{MW}$ (SCB-DFB) and $56 \mathrm{MW}$ (SCB-CFB). These energy losses represent an increase in terms of energy content related to the power output of each configuration of $11 \%$ (SCB-DFB) and $32 \%$ (SCB-CFB).

\section{CONCLUSION}

The case study demonstrated the potential of the sugarcane bagasse (SCB) in Brazil to be used as a feedstock in thermochemical conversion systems for energy generation. Since the Brazilian sugarcane industry generates large amounts of SCB during the crop season. Among the thermochemical systems, the fluidized bed gasifier was selected as a conversion technology. It represents a promising system proven to be beneficial for biomass gasification at achieving higher efficiencies. However, it is still under development. In this sense, the techno-economic assessment of the gasification systems coupled with a combined cycle shows that the dual fluidized bed configuration has the lowest total cost of investment (TCI) in comparison with the circulating model. Indeed, the lignocellulosic biomass gasification through the SCB-DFB model has a reduction of $15 \%$ of the CAPEX compared to the SCB-CFB system. Hence, the SCB-DFB model presents a competitive advantage since the former provides more product output (NPC) per year. Besides, this investment cost could be viable in the Brazilian market compared with typical NPC values for conventional power systems (i.e., coal and nuclear plants). These favorable conditions were obtained via heat integration, which allowed savings in net productions costs related to steam consumption (i.e., process integration between the gasifier unit and the combined cycle).

From the exergetic analysis point of view, the SCB-DFB model shows that the sugarcane bagasse offers a promising configuration since it reported the lowest exergy destruction rate; as a consequence, the highest exergy efficiency of the overall systems of all integrated gasification systems and power generation scenarios investigated. In this regard, it is noted that a sensitivity analysis focused on exploring the effect of the operation time on the specific production costs was carried out for each system. In addition, a sensitivity analysis for the SCB-DFB case changing the compressor pressure ratio in the combined cycle section and varying the key variables related to 
the feedstock price and equipment assumptions adopted in the NPC calculation was performed to determine the optimal parameters. Hence, this configuration represents an application of value-added from biomass supply chain residues. This fact could contribute to determining the potential of lignocellulosic biomass toward energy diversification.

Last, the conceptual development of the biomass supply chains could be analyzed to explore other products and possibilities including feedstock production and collection, gasification, syngas conditioning, and downstream processing. For instance, the valorization of the syngas and by-products could be covered in future research through technological scenarios that assess the syngas conversion into biofuel production (i.e., FT products achieved an increase of 11 and $32 \%$ related to the power output of SCB-CFB and SCB-DFB configurations), bulk-chemical/fuels, or hybrid systems (chemical, fuels, and power generation).

\section{DATA AVAILABILITY STATEMENT}

The original contributions presented in the study are included in the article/Supplementary Material; further inquiries can be directed to the corresponding authors.

\section{REFERENCES}

AACE International (2011). "Cost Estimate Classification System - as Applied in Engineering, Procurement, and Construction for the Process Industries," in Morgantown, United State: Association of the Advancement of Cost Engineering. https://web.aacei.org.

Ahmed, I. I., and Gupta, A. K. (2012). Sugarcane Bagasse Gasification: Global Reaction Mechanism of Syngas Evolution. Appl. Energ. 91 (1), 75-81. doi:10.1016/j.apenergy.2011.07.001

Albrecht, F. G., König, D. H., Baucks, N., and Dietrich, R.-U. (2017). A Standardized Methodology for the Techno-Economic Evaluation of Alternative Fuels - A Case Study. Fuel 194 (April), 511-526. doi:10.1016/ j.fuel.2016.12.003

AlNouss, A., McKay, G., and Al-Ansari, T. (2019). A Techno-EconomicEnvironmental Study Evaluating the Potential of Oxygen-Steam Biomass Gasification for the Generation of Value-Added Products. Energ. Convers. Manage. 196 (September), 664-676. doi:10.1016/j.enconman.2019.06.019

Anukam, A., Mamphweli, S., Reddy, P., Meyer, E., and Okoh, O. (2016). PreProcessing of Sugarcane Bagasse for Gasification in a Downdraft Biomass Gasifier System: A Comprehensive Review. Renew. Sust. Energ. Rev. 66 (December), 775-801. doi:10.1016/j.rser.2016.08.046

Asadullah, M. (2014). Barriers of Commercial Power Generation Using Biomass Gasification Gas: A Review. Renew. Sust. Energ. Rev. 29 (January), 201-215. doi:10.1016/j.rser.2013.08.074

Bakshi, B. R. (2019). Sustainable Engineering. Cambridge University Press. doi:10.1017/9781108333726

Basu, P. (2018). Biomass Gasification, Pyrolysis and Torrefaction. Practical Design and Theory. 3rd ed. Elsevier.

Benalcázar, E. A., Deynoot, B. G., Noorman, H., Osseweijer, P., and Posada, J. A. (2017). Production of Bulk Chemicals from Lignocellulosic Biomass via Thermochemical Conversion and Syngas Fermentation: a Comparative Techno-economic and Environmental Assessment of Different Site-specific Supply Chain Configurations. Biofuels, Bioprod. Bioref. 11 (5), 861-886. doi:10.1002/bbb.1790

Broer, K. M., and Peterson., C. (2019). "Gasification," in Thermochemical Processing Of Biomass. 2nd ed. (John Wiley \& Sons), 85-123. doi:10.1002/ 9781119417637.ch4

\section{AUTHOR CONTRIBUTIONS}

Conceptualization and methodology design: PS, SM, and JP; data analysis and validation: PS, SM, and AP; writing-original draft preparation: PS, SM, AP, and JP; supervision: R-UD and JP; project administration: R-UD, RM, and JP.

\section{FUNDING}

This research was conducted within a FAPESP-BIOEN thematic research project, 2015/20630-4. The authors acknowledge the São Paulo Research Foundation (FAPESP) for grants 2017/03091-8 and 2017/16106-3. Furthermore, SM and R-UD gratefully acknowledge the financial support from the strategic project "Future Fuels" of the German Aerospace Center (DLR).

\section{SUPPLEMENTARY MATERIAL}

The Supplementary Material for this article can be found online at: https://www.frontiersin.org/articles/10.3389/fceng.2021.727068/ full\#supplementary-material

Camacho-ardila, Y., Figueroa, J., Lunelli, B. H., Filho, R. M., and Maciel, M. R. (2012). "Syngas Production from Sugar Cane Bagasse in a Circulating Fluidized Bed Gasifier Using Aspen Plus," in Proceedings 22nd European Symposium on Computer Aided Process Engineering, London-UK (Elsevier). doi:10.1016/ b978-0-444-59520-1.50077-4

Corella, J., Toledo, J. M., and Molina, G. (2007). A Review on Dual Fluidized-Bed Biomass Gasifiers. Ind. Eng. Chem. Res. 46, 6831-6839. doi:10.1021/ie0705507

da Silva, E. B., Assato, M., and de Lima, R. C. (2013). Performance Prediction of Gas Turbine under Different Strategies Using Low Heating Value FuelIn. American Society of Mechanical Engineers Digital Collection. doi:10.1115/GT2013-96013

Damartzis, T., and Zabaniotou, a. (2011). Thermochemical Conversion of Biomass to Second Generation Biofuels through Integrated Process Design-A Review. Renew. Sust. Energ. Rev. 15 (1), 366-378. doi:10.1016/j.rser.2010.08.003

de Medeiros, E. M., Posada, J. A., Noorman, H., Osseweijer, P., and Filho, R. M. (2017). Hydrous Bioethanol Production from Sugarcane Bagasse via Energy Self-Sufficient Gasification-Fermentation Hybrid Route: Simulation and Financial Analysis. J. Clean. Prod. 168 (December), 1625-1635. doi:10.1016/ j.jclepro.2017.01.165

Emun, F., Gadalla, M., Majozi, T., and Boer, D. (2010). Integrated Gasification Combined Cycle (IGCC) Process Simulation and Optimization. Comput. Chem. Eng. 34 (3), 331-338. doi:10.1016/ j.compchemeng.2009.04.007

Energy Technologies Institute. 2020. "Delivering the UK's Future Energy Technologies." Bioenergy Project: TEA Biomass Pre-processing DownSelection and Workshop Report. Energy Technologies Institute - ETI. Available at: https://data.ukedc.rl.ac.uk/browse/edc/renewables/bioenergy/ TEAB/TEAB_Reports/.(Accessed November 9, 2020).

EPE. 2019. Brazilian Energy Research Company. Available at: http://www.epe.gov.br. Esmaili, E., Mostafavi, E., and Mahinpey, N. (2016). Economic Assessment of Integrated Coal Gasification Combined Cycle with Sorbent CO2 Capture. Appl. Energ. 169 (May), 341-352. doi:10.1016/j.apenergy.2016.02.035

Gómez-Barea, A., and Leckner, B. (2010). Modeling of Biomass Gasification in Fluidized Bed. Prog. Energ. Combustion Sci. 36 (4), 444-509. doi:10.1016/ j.pecs.2009.12.002

Hanchate, N., Ramani, S., Mathpati, C. S., and Dalvi, V. H. (2021). Biomass Gasification Using Dual Fluidized Bed Gasification Systems: A Review. J. Clean. Prod. 280 (January), 123148. doi:10.1016/j.jclepro.2020.123148 
Hannula, I. (2016). Hydrogen Enhancement Potential of Synthetic Biofuels Manufacture in the European Context: A Techno-Economic Assessment. Energy 104 (June), 199-212. doi:10.1016/j.energy.2016.03.119

Heinze, C., May, J., Peters, J., Ströhle, J., and Epple, B. (2019). Techno-Economic Assessment of Polygeneration Based on Fluidized Bed Gasification. Fuel 250 (August), 285-291. doi:10.1016/j.fuel.2019.04.020

International Renewable Energy Agency (2016). Innovation Outlook Advanced Liquid Biofuels. IRENA. Available at: https://www.irena.org/.

Kim, H., Lee, S., Lee, B., Park, J., Lim, H., and Won, W. (2021). Improving Revenue from Lignocellulosic Biofuels: An Integrated Strategy for Coproducing Liquid Transportation Fuels and High Value-Added Chemicals. Fuel, 287. October, 119369, 2021 . Fuel. doi:10.1016/j.fuel.2020.119369

Kotas, T. J. (1985). The Exergy Method of Thermal Plant Design. London-UK: Butterworths.

Liu, Z., and Karimi, I. A. (2018). Simulation and Optimization of a Combined Cycle Gas Turbine Power Plant for Part-Load Operation. Chem. Eng. Res. Des. 131 (March), 29-40. doi:10.1016/j.cherd.2017.12.009

Marais, H., van Schoor, G., and Uren, K. R. (2019). The Merits of Exergy-Based Fault Detection in Petrochemical Processes. J. Process Control. 74, 110-119. November. doi:10.1016/j.jprocont.2017.11.005

Mehrpooya, M., Khalili, M., and Sharifzadeh, M. M. M. (2018). Model Development and Energy and Exergy Analysis of the Biomass Gasification Process (Based on the Various Biomass Sources). Renew. Sust. Energ. Rev. 91 (August), 869-887. doi:10.1016/j.rser.2018.04.076

Molino, A., Larocca, V., Chianese, S., and Musmarra, D. (2018). Biofuels Production by Biomass Gasification: A Review. Energies 11 (4), 811. doi:10.3390/en11040811

Nikoo, M. B., and Mahinpey., N. (2008). Simulation of Biomass Gasification in Fluidized Bed Reactor Using ASPEN PLUS. Biomass and Bioenergy 32 (12), 1245-1254. doi:10.1016/j.biombioe.2008.02.020

Niu, M., Xie, J., Liang, S., Liu, L., Wang, L., and Peng, Y. (2021). Simulation of a New Biomass Integrated Gasification Combined Cycle (BIGCC) Power Generation System Using Aspen Plus: Performance Analysis and Energetic Assessment. Int. J. Hydrogen Energ. 46 (43), 22356-22367. doi:10.1016/ j.ijhydene.2021.04.076

Nogueira, L. A. H., Seabra, J. E. A., and Macedo, I. C. (2011). "Biomass Gasification for Ethanol Production," in In Routes To Cellulosic Ethanol. Editors M. S. Buckeridge and G. H. Goldman (New York, NY: Springer), 27-41. doi:10.1007/978-0-387-92740-4_3

Ofori-Boateng, C., and Lee, K. T. (2013). Comparative Thermodynamic Sustainability Assessment of Lignocellulosic Pretreatment Methods for Bioethanol Production via Exergy Analysis. Chem. Eng. J. 228 (July), 162-171. doi:10.1016/j.cej.2013.04.082

Patuzzi, F., Basso, D., Vakalis, S., Antolini, D., Piazzi, S., Benedetti, V., et al. (2021). State-of-the-Art of Small-Scale Biomass Gasification Systems: An Extensive and Unique Monitoring Review. Energy 223 (May), 120039. doi:10.1016/ j.energy.2021.120039

Peters, M., Timmerhaus, K., and West, R. (2003). Plant Design and Economics for Chemical Engineers. New York, United States: McGraw-Hill Education.

Pregger, T., Schiller, G., Cebulla, F., Dietrich, R.-U., Maier, S., Thess, A., et al. (2020). Future Fuels-Analyses of the Future Prospects of Renewable Synthetic Fuels. Energies 13 (1), 138. doi:10.3390/en13010138

Ptasinski, Krzysztof. (2016). "Exergy Analysis," in Efficiency of Biomass Energy: An Exergy Approach to Biofuels, Power, and Biorefineries (John Wiley \& Sons), 37-90. doi:10.1002/9781119118169.ch2

Rahimi, M. J., Hamedi, M. H., Amidpour, M., and Livani, E. (2020). Technoeconomic Evaluation of a Gasification Plant: Modeling, Experiment and Software Development. Waste Biomass Valor. 11, 6815-6840. February. doi:10.1007/s12649-019-00925-1

Rupesh, S., Muraleedharan, C., and Arun, P. (2016). Energy and Exergy Analysis of Syngas Production from Different Biomasses through Air-Steam Gasification. Front. Energ. 14, 607-619. December. doi:10.1007/s11708-016-0439-1
Safarian, S., Unnpórsson, R., and Richter, C. (2019). A Review of Biomass Gasification Modelling. Renew. Sust. Energ. Rev. 110 (August), 378-391. doi:10.1016/j.rser.2019.05.003

Shahabuddin, M., Krishna, B. B., Bhaskar, T., and Perkins, G. (2020). Advances in the Thermo-Chemical Production of Hydrogen from Biomass and Residual Wastes: Summary of Recent Techno-Economic Analyses. Bioresour. Tech. 299 (March), 122557. doi:10.1016/j.biortech.2019.122557

Silva, I. P., Lima, R. M. A., LimaRuzene, G. F., Ruzene, D. S., and Silva, D. P. (2019). Thermodynamic Equilibrium Model Based on Stoichiometric Method for Biomass Gasification: A Review of Model Modifications. Renew. Sust. Energ. Rev. 114 (October), 109305. doi:10.1016/j.rser.2019.109305

Silva Ortiz, P., and de Oliveira, S. (2014). Exergy Analysis of Pretreatment Processes of Bioethanol Production Based on Sugarcane Bagasse. Energy 76 (November), 130-138. doi:10.1016/j.energy.2014.04.090

Silva, V. B., and Rouboa, A. (2014). Predicting the Syngas Hydrogen Composition by Using a Dual Stage Equilibrium Model. Int. J. Hydrogen Energ. 39 (1), 331-338. doi:10.1016/j.ijhydene.2013.10.053

Sousa Cardoso, J., Silva, V., Eusébio, D., Lima Azevedo, I., Tarelho, L. A. C., and Tarelho, C. (2020). Techno-Economic Analysis of Forest Biomass Blends Gasification for Small-Scale Power Production Facilities in the Azores. Fuel 279 (November), 118552. doi:10.1016/j.fuel.2020.118552

Szargut, J., Morris, D., and Steward, F. (1988). Exergy Analysis of Thermal, Chemical and Metallurgical Processes. New York: Hemisphere Publishing Corporation.

Toscano Miranda, N., Lopes Motta, I., Maciel Filho, R., and Wolf Maciel, M. R. (2021). Sugarcane Bagasse Pyrolysis: A Review of Operating Conditions and Products Properties. Renew. Sust. Energ. Rev. 149 (October), 111394. doi:10.1016/j.rser.2021.111394

Watanabe, M. D. B., Morais, E. R., Cardoso, T. F., Chagas, M. F., Junqueira, T. L., Carvalho, D. J., et al. (2020). Process Simulation of Renewable Electricity from Sugarcane Straw: Techno-Economic Assessment of Retrofit Scenarios in Brazil. J. Clean. Prod. 254 (May), 120081. doi:10.1016/j.jclepro.2020.120081

Weiland, N. T., and White, C. W. (2018). Techno-Economic Analysis of an Integrated Gasification Direct-Fired Supercritical CO2 Power Cycle. Fuel 212 (January), 613-625. doi:10.1016/j.fuel.2017.10.022

Worley, M., and Yale, M. (2012). Biomass Gasification Technology Assessment: Consolidated Report (Technical Report). Golden, CO. United States: National Renewable Energy Lab. (NREL). https://www.osti.gov/biblio/1059145.

Zornek, T., Monz, T., and Aigner, M. (2015). Performance Analysis of the Micro Gas Turbine Turbec T100 with a New FLOX-Combustion System for Low Calorific Fuels. Appl. Energ. 159 (December), 276-284. doi:10.1016/ j.apenergy.2015.08.075

Conflict of Interest: The authors declare that the research was conducted in the absence of any commercial or financial relationships that could be construed as a potential conflict of interest.

The handling Editor declared a past co-authorship/collaboration with the authors (PS, JP, RM).

Publisher's Note: All claims expressed in this article are solely those of the authors and do not necessarily represent those of their affiliated organizations, or those of the publisher, the editors and the reviewers. Any product that may be evaluated in this article, or claim that may be made by its manufacturer, is not guaranteed or endorsed by the publisher.

Copyright (๑) 2021 Silva Ortiz, Maier, Dietrich, Pinto Mariano, Maciel Filho and Posada. This is an open-access article distributed under the terms of the Creative Commons Attribution License (CC BY). The use, distribution or reproduction in other forums is permitted, provided the original author(s) and the copyright owner(s) are credited and that the original publication in this journal is cited, in accordance with accepted academic practice. No use, distribution or reproduction is permitted which does not comply with these terms. 